\title{
Lidil
}

Revue de linguistique et de didactique des langues

$35 \mid 2007$

Figures de l'auteur en didactique

\section{Lidil en mutation}

Francis Grossmann, Catherine Brissaud et Marielle Rispail

\section{(2) OpenEdition}

Journals

Édition électronique

URL : http://journals.openedition.org/lidil/2123

DOI : $10.4000 /$ lidil.2123

ISSN : 1960-6052

\section{Éditeur}

UGA Éditions/Université Grenoble Alpes

\section{Édition imprimée}

Date de publication : 1 juin 2007

Pagination : 5-7

ISBN : 978-2-84310-100-7

ISSN : 1146-6480

\section{Référence électronique}

Francis Grossmann, Catherine Brissaud et Marielle Rispail, «Lidil en mutation », Lidil [En ligne], 35 | 2007, mis en ligne le 19 décembre 2013, consulté le 23 septembre 2020. URL : http://

journals.openedition.org/lidil/2123; DOI : https://doi.org/10.4000/lidil.2123

Ce document a été généré automatiquement le 23 septembre 2020

(C) Lidil 


\title{
Lidil en mutation
}

\author{
Francis Grossmann, Catherine Brissaud et Marielle Rispail
}

1 La revue Lidil est née en 1989, fondée par Louise Dabène, alors directrice du laboratoire de linguistique et de didactique des langues étrangères et maternelles (Lidilem). A une exception près, deux numéros par an ont régulièrement vu le jour. Le volume de la revue a grandi au fil des numéros : de 124 pages $\left(n^{\circ} 1\right)$, il est passé progressivement à environ 200 pages.

2 Une autre mutation perceptible est sensible dans le nom même de la revue : le $\mathrm{n}^{\circ} 1$ était sous-titré « Revue de didactique des langues », transformé en « Revue de linguistique et de didactique des langues » dès le $n^{\circ} 2$. Depuis lors, la revue s'est toujours efforcée de tenir une ligne éditoriale ouverte permettant de traiter les problématiques linguistiques - et sociolinguistiques - en tant que telles, tout en les articulant, chaque fois que c'était possible, aux questions spécifiques de la didactique des langues. On note également la prise en compte de thématiques liées à l'acquisition, direction de recherche qui s'est développée ces dernières années au sein du Lidilem.

Disons un mot des évolutions structurelles. Il y a d'abord l'évolution naturelle des comités de rédaction et comité scientifique, conséquence des départs en retraite et des recrutements opérés au laboratoire Lidilem. Jusqu'au n ${ }^{\circ} 17$, c'est Louise Dabène qui est rédactrice en chef; à partir du no 18 (paru en novembre 1998), c'est Jacqueline Billiez, fidèle du comité de rédaction depuis la première heure, qui prend en main la revue. Avec le $n^{\circ} 27$, en juillet 2003, une secrétaire de rédaction, Catherine Brissaud, vient épauler Jacqueline Billiez; le conseil scientifique s'élargit et les articles sont désormais systématiquement anonymisés.

4 Revue du laboratoire Lidilem, permettant souvent aux doctorants d'écrire leur premier article, la revue s'est toujours également inscrite dans des réseaux de collaborations extérieures. Cette diversité des apports a été progressivement renforcée, et la revue procède aujourd'hui, pour chaque numéro, à des appels à contributions, à partir de thématiques liées aux axes de recherche du quadriennal et aux projets scientifiques développés au sein du laboratoire.

5 Avec le $n^{\circ} 34$, fin 2006, Jacqueline Billiez cède sa place à Francis Grossmann et le conseil scientifique est renommé «comité de lecture », selon l'appellation en vigueur dans la 
plupart des revues scientifiques, les membres du Comité de lecture offrant leur expertise au cours du processus rédactionnel, et se portant garant de la qualité scientifique de la revue, tâche que remplissait jusque là le « comité scientifique». Pour faire face aux besoins, nous préparons un nouvel élargissement de ce comité de lecture, conséquent, qui entrera en vigueur dès le prochain numéro.

6 Signalons qu'avec le présent numéro, contraint par la mise en ligne prochaine de Lidil, nous avons procédé à une nouvelle répartition des tâches : Francis Grossmann prend le titre de directeur de la revue, Catherine Brissaud celui de rédactrice en chef, tandis que Marielle Rispail occupe désormais la fonction de secrétaire de rédaction. La revue, dont le nom même traduit suffisamment l'ancrage au sein du laboratoire Lidilem, dirigé à présent par Jean-Pierre Chevrot, assume désormais son autonomie en tant que revue scientifique à part entière.

7 La mise en ligne de la revue représente à présent une nouvelle étape nécessaire. Elle permettra d'abord une meilleure diffusion, à l'heure où les contraintes budgétaires limitent les envois postaux, dont les coûts ont augmenté considérablement ces dernières années. Mais cet argument économique n'est pas le seul : nous pensons que la revue pourra ainsi trouver, un nouveau public, d'étudiants, de chercheurs et de formateurs, et ce aussi bien en France qu'à l'étranger. Le choix par les Ellug de s'adresser à revues.org pour assurer la mise en ligne nous parait de bon augure : il s'agit en effet du plus ancien portail français de revues scientifiques en ligne, et surtout, il est directement issu de la communauté scientifique et il est reconnu à l'échelle tant nationale qu'internationale. Ajoutons que contrairement à d'autres portails, il n'a pas de vocation mercantile. Lidil devrait donc, grâce à lui, gagner en visibilité.

8 Nous voudrions, pour terminer, rendre un chaleureux hommage à Jacqueline Billiez qui a participé à la fondation de la revue en 1989 et qui n'a cessé d'oeuvrer pour Lidil, dixhuit années durant. Sous son influence, la revue Lidil a continué à grandir, et à acquérir le rayonnement scientifique qui est le sien aujourd'hui. Le travail de Jacqueline Billiez pour Lidil n'est d'ailleurs pas terminé, puisqu'elle ne cesse pas de nous apporter son expérience et ses conseils: les remerciements sont donc prématurés, mais non la gratitude! 